IP Periodica Polytechnica

Transportation Engineering

43(2), pp. 55-66, 2015

DOI: 10.3311/PPtr.7543

Creative Commons Attribution (i)

RESEARCH ARTICLE

\section{Examination of Lattice-like Structure for Vehicle Preliminary Design}

\author{
Péter Harth ${ }^{1}$, Pál Michelberger $\dagger^{2}$
}

Received 30 May 2014

\begin{abstract}
In this paper the examination of lattice-like structure is introduced. Lattice structures are built of crossmembers, side-wall and longitudinal beams. Both the crossmember and the beams can be symmetric, but the paper deals global symmetry of lattice. This global symmetry means a longitudinal and lateral symmetry plane of the structure. Similarly to the structure, the outer load can be symmetric or antimetric for these two symmetry planes, as well. The main purpose of this paper is to show reduction the number of the unknowns of the compatibility equation and predict the distribution of the bending moment in beams for practical use.
\end{abstract}

\section{Keywords}

Lattice-like structure, commercial vehicle lattice structure, commercial vehicle preliminary design, symmetric and antimetric load, bending moment distribution on longitudinal and side-wall beams

\section{Nomenclatures}

a Distance between side-wall and longitudinal beams [m]

b Distance between two longitudinal beams [m]

$\mathrm{L}$ Distance between two crossmembers [m]

C Constant for the calculation [-]

$\mathrm{D}_{1} \quad$ Constant for the calculation [Nm]

$\mathrm{D}_{2} \quad$ Constant for the calculation [Nm]

F Load (outer) [N]

$\mathrm{Q}_{0} \quad$ Shear from the outer load [N]

$\mathrm{M}_{0} \quad$ Bending moment from the outer load [Nm]

E Young Modulus [MPa]

G Shear Modulus [MPa]

A Crossmember cross-section area $\left[\mathrm{m}^{2}\right]$

A' Side-wall beam cross-section area $\left[\mathrm{m}^{2}\right]$

A" Longitudinal beam cross-section area $\left[\mathrm{m}^{2}\right]$

I Crossmember bending inertia $\left[\mathrm{m}^{4}\right]$

I' Side-wall bending inertia $\left[\mathrm{m}^{4}\right]$

I" Longitudinal bending inertia $\left[\mathrm{m}^{4}\right]$

$\gamma \quad$ Parameter for bending [-]

$\gamma$ Parameter for shear [-]

$\mathrm{k} \quad$ Indices of the unknowns [-]

$\mathrm{m}$ number of beams [-]

$\mathrm{n}$ number of crossmember [-]

$\delta_{\mathrm{ij}} \quad$ Coefficient of the comp. matrix $\left[1 / \mathrm{m}^{3}\right]$

$\delta_{0 \mathrm{j}} \quad$ Coefficient of the constant $\left[\mathrm{N} / \mathrm{m}^{2}\right]$

\section{Introduction}

This paper deals with statically indetermined lattice-like structure analysis. The statically indetermined structure can be only designed by reduction or iteration due to the huge amount of governing equations and unknowns. Preliminary design based on simplification and approximation, and a simple mathematical model using is recommended. The main purpose of this paper is to reduce the number of the unknowns of the compatibility equation, in addition examine the bending moment on the longitudinal and side-wall beams function of the different orth. groups. In the following, bending moment from the outer act only on longitudinal beams, thus giving advantage to the commercial vehicle (under-body or roof) structure preliminary

\footnotetext{
1 Department of Automobiles and Vehicle Manufacturing, Faculty of Transportation Engineering and Vehicle Engineering, Budapest University of Technology and Economics,

H-1521 Budapest, P. O. B. 91, Hungary

${ }^{2}$ Department of Vehicle Elements and Vehicle- Structure Analysis, Faculty of Transportation Engineering and Vehicle Engineering, Budapest University of Technology and Economics, H-1521 Budapest, P. O. B. 91, Hungary

*Corresponding author, e-mail: harth.peter@auto.bme.hu
} 
design. There is a non vehicles application of the lattice structure in (Pristyák, 1997). It is worth to examine the distribution of the bending moment if the outer load acts only on side-wall beams, but the applied basic system is need to be modified and the whole analysis is too long to be included in this paper.

Lattice-like structures are significant in road vehicles chassis and frame. Vehicle frames, bus floor frames or a complete vehicle can be modelled as lattice. There is another application for lattice-like structures. (Schilling, 1925) Exact and approximate methods have been developed for the calculation of lattice-like structure based on the force and the displacement method (Palotás, 1953). Two types of lattice are used in practice. One is poor resistance to torsion, the other is torsional resistance. In the following this paper deals with lattice structures which are poor resistance to torsion. The main load in lattice comes from weight force, longitudinal and lateral acceleration of the vehicle. Contrary to the planar-frame structures (Harth and Michelberger, 2014), here the planar load is taking out of consideration. The paper only involves the examination of perpendicular load which can be acted only on node. The task in these structures is to make the planar lattice to be able working under perpendicular load. Node is an intersection where beam and crossmember intersect each other and the contact faces surrender only force.

In the following, two internal load components (shear and bending) are taken into consideration applying the principle of work. The stress distribution in the cross sections caused by shear is neglected.

There are three different size are existing in practice. The first case is when the sides of lattice are built from equal number of field, and either is even. These structures were examined in (Michelberger, 1968). The second case is when lattice is built from equal number field, and either is odd. The third case is when lattice is built from different number of fields. One is even the other is odd.

Henceforward, size of lattice structure is featured with number of longitudinal beams and crossmembers. Two of longitudinal beams called side-wall beams are usually have different property (cross-section area, bending inertia). Side-wall is connected to the side-wall beam with welding. Similar to the side-wall beam, first and last crossmember have usually different inertia properties from the inner crossmembers because the front and rear panel. The most generally used beam number is between 4 and 5, and crossmember number is between 6 and 8 in buses and coaches. Erz examined the torsion of the structure with 2 longitudinal beams, Michelberger extended out to 4 longitudinal beams (Erz, 1957).

On Fig. 1 a well-known city bus can be seen with 8 crossmember in the forward section and 5 crossmembers in the rear section.

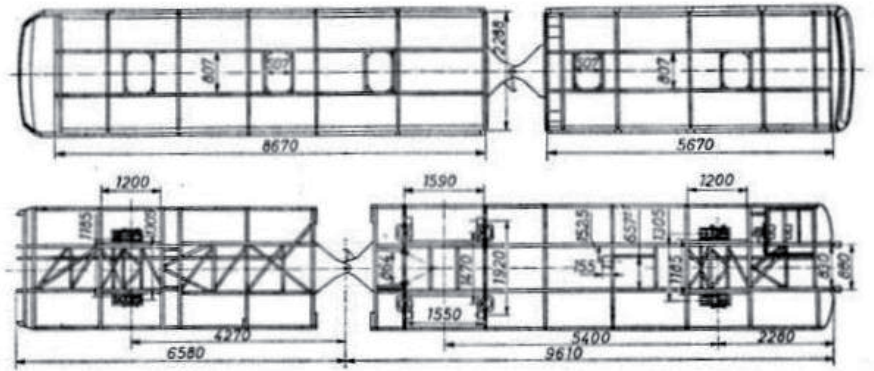

Fig. 1 Ikarus 280 frame structure (Source: http://forum.index.hu/Article/show Article $? \mathrm{t}=9043237 \& \mathrm{go}=124004285 \& \mathrm{p}=1$ )

\section{Description of lattice model}

Examined lattice structure has two symmetry planes. One is the longitudinal symmetry plane; the other is lateral symmetry plane. To distinguish the two symmetry planes, the longitudinal plane is always parallel with the course. Number of beams is $m$, and number of crossmembers is $n$.

In this model the crossmembers have the same properties, but the side-wall and longitudinal beams can be different because the side-wall. The most obviously difference is in bending inertias and in cross-section area. The examined model is parametric in aspect of $a, b, L, A, A^{\prime}, A^{\prime \prime}, I, I^{\prime}, I^{\prime \prime}, E$, and $G$. Applied marking: $a$ : distance between side-wall and longitudinal beam, $b$ : distance between two longitudinal beams, $L$ : distance between two crossmembers, $I$ : crossmember bending inertia, $A$ : crossmember cross-section area, $I^{\prime}$ : side-wall bending inertia, $A$ ': side-wall cross-section area, $I$ ": longitudinal beam bending inertia, $A$ ": longitudinal beam cross-section area.

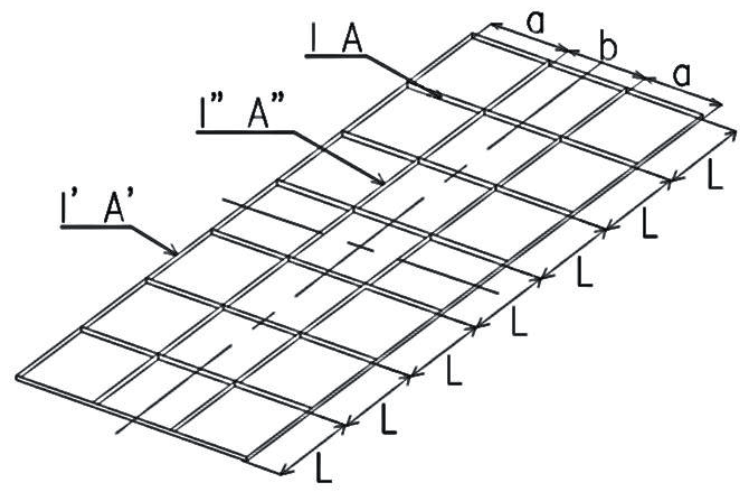

Fig. 2 Inertias and cross-section areas of the lattice structure

This structure on Fig. 2 is statically indetermined at $(m-2)$ $(n-2) / 4$. The lattice structure becomes statically determined (statically determined basic system) with slices in the intersection at the side-wall beam and joined by hinges. The crossmembers and longitudinal beam are connected with spherical joints to each other. All the beams (side-wall and inner) and crossmembers are considered to be of constant stiffness and crossmember to be of identical stiffness. This model is applicable, when the stiffness of the crossmembers are equal in couples. (In this case: instead of $I$, the $I_{1}, I_{2} \ldots I_{k}$ inertias are applied) 
Symmetry about the longitudinal plane is general, but lateral plane is assumed, thus helping the preliminary design work. The bending moment distribution on beams can be divided:

- in the ration of the $I^{\prime}$ and $I^{\prime}$ ' bending inertias in symmetric case (Michelberger, 1968) and

- in the ratio of the $I$ ' and I" furthermore $a$ and $b$ in antimetric case

if $I \rightarrow \infty$ and load acts on crossmember.

In the practice the bending inertia of the crossmember is finite, thus the paper is examined the distribution of the bending moment on beams in the function of the crossmember stiffness.

In this paper the symmetric and antimetric loads are introduced. The number of the unknowns is $k$ in the examined lattice-like structures.

$$
\begin{gathered}
k=\frac{n-2}{2} \quad \text { if } n \text { is even, or } \\
k=\frac{n-1}{2} \quad \text { if } n \text { is odd }
\end{gathered}
$$

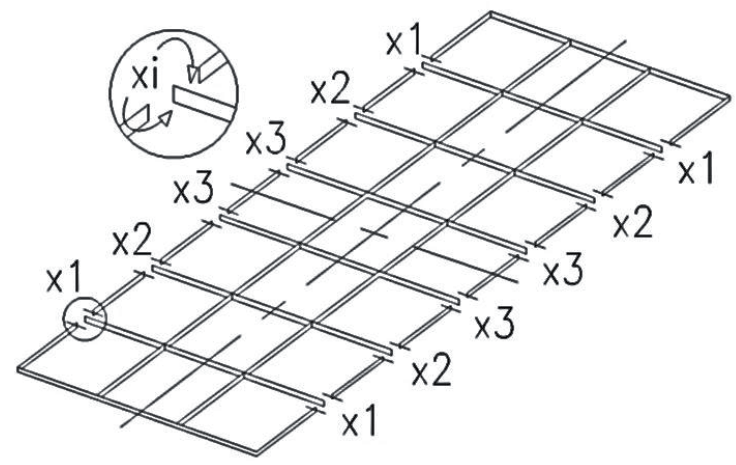

Fig. 3 Statically determined basic system ( $n$ is even)

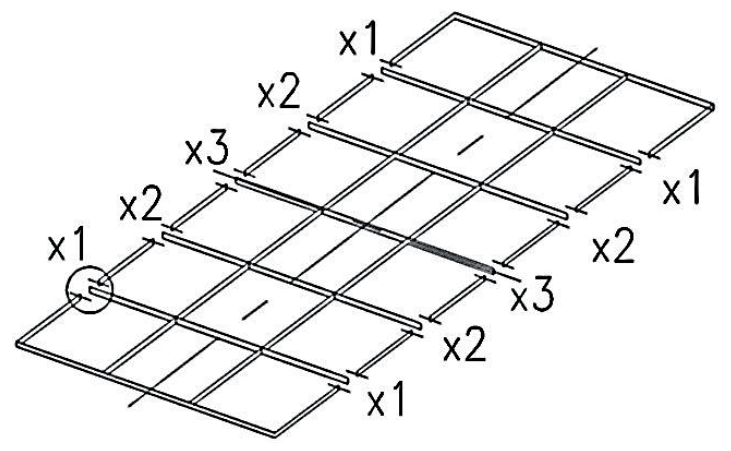

Fig. 4 Statically determined basic system ( $n$ is odd)

\section{Applied load system}

Bending moment preliminary distribution (estimation) on beams can be only applied if the outer load acts on crossmembers.

If the outer load act on longitudinal or side-wall beam Palotás offer a method for solution. (Palotás, 1953)

In our examination outer load can act only on node of the longitudinal beam.
In the best case crossmember is loaded uniformly called elementary load case. To apply our load it is needed a force system which is in static balance. An elementary and an equilibrium force system acts on crossmembers (Fig. 5-7). The summarized force system can be symmetric or antimetric for longitudinal and lateral symmetry planes. In the following paper examined lattices are consist 4 beams and 8 crossmembers.

The other case where outer load is acting between two nodes was worked out by Palotás (Palotás, 1953).

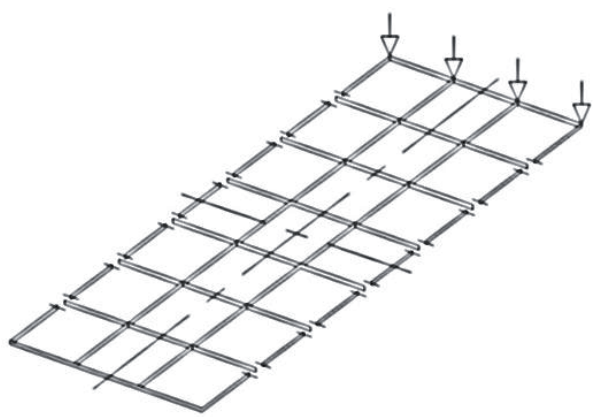

Fig. 5 Elementary force system

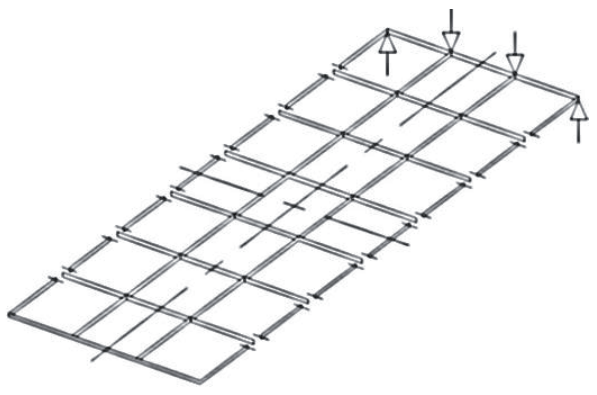

Fig. 6 Equilibrium force system

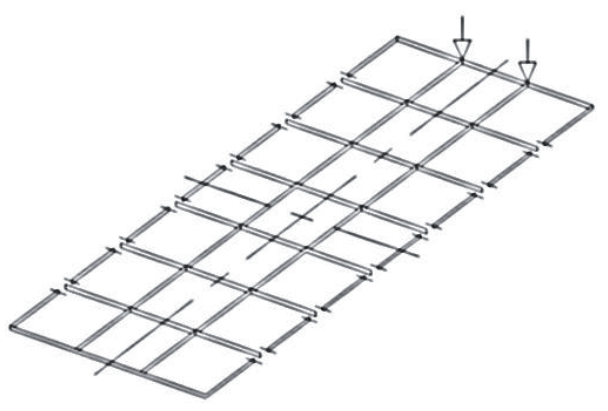

Fig. 7 Summarized force system

If the outer load is symmetric for the longitudinal symmetry plane called $\mathrm{S}_{1}$, if antimetric called $\mathrm{A}_{1}$. If the load is symmetric for the lateral symmetry plane called $\mathrm{S}_{2}$, if antimetric called $\mathrm{A}_{2}$.

In the following, examination of a lattice structure with 4 longitudinal beams 8 crosmembers are introduced, applying two symmetry planes offering a fast approximation of bending moment to ease preliminary decision and to evaluate the effect of necessary further modifications.

The load can be (in shorter form) $\mathrm{S}_{1} \mathrm{~S}_{2}, \mathrm{~S}_{1} \mathrm{~A}_{2}$ and $\mathrm{A}_{1} \mathrm{~S}_{2}$, but cannot be $A_{1} A_{2}$ because under this load case the structure becomes instable (poor resistance to torsion) (Fig. 8 - Fig. 11). 


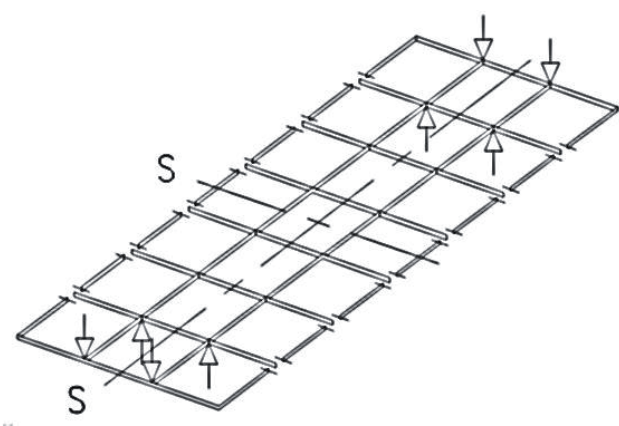

Fig. $8 \mathrm{~S}_{1} \mathrm{~S}_{2}$ load case (weight load)

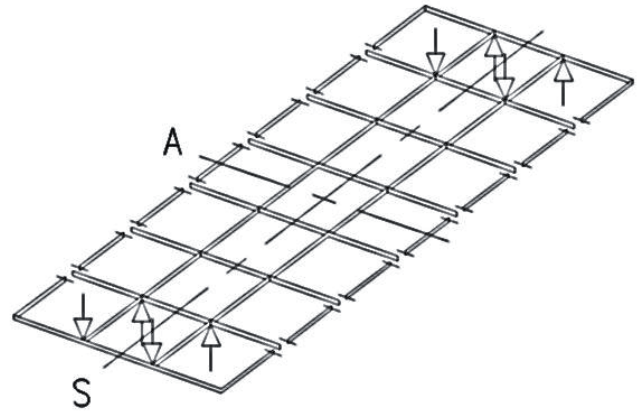

Fig. $9 \mathrm{~S}_{1} \mathrm{~A}_{2}$ load case (acceleration or deceleration)

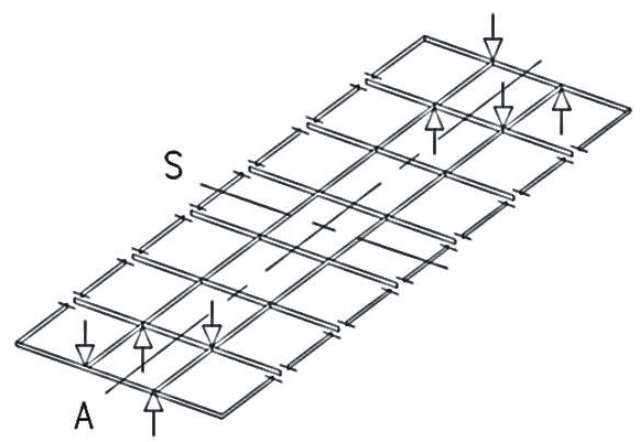

Fig. $10 \mathrm{~A}_{1} \mathrm{~S}_{2}$ load case (turning)

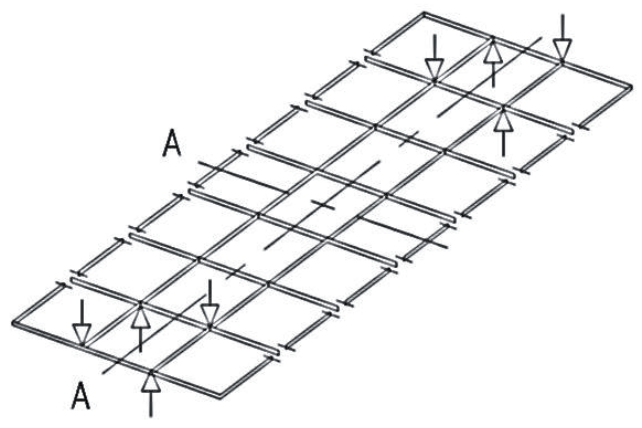

Fig. $11 \mathrm{~A}_{1} \mathrm{~A}_{2}$ load case (kinematic load-torsion)

The deformation caused by shear force is taking into consideration in the model at first, but if it possible to neglect to make the model more easier for practice using. Take consider the bending moment developing in the side-wall beam at cuts above the crossmember due to unknown internal forces (moment) in the regular lattice with stiff crossmember is of the form:

$$
\mathrm{Dx}+\mathrm{d}=0
$$

Bending moment and shear from $x 1$ unit load are calculated for coefficients of the compatibility equation. The matrix coefficients of the compatibility equations are denoted by $\delta_{i j}$, where $i, j=\{0,1,2, \ldots \mathrm{k}\}$ considering the symmetry of load.

The indices $i$ means that $x i$ unit load act on the $j$ th $(1<j \leq n-1)$ crossmember. If the indices $i=0$, that means the constant coefficient.

\section{Fully symmetric loads $\left(\mathbf{S}_{1} \mathbf{S}_{2}\right)$}

This load case is the most generally with symmetric weight load in the front and rear axle. This model illustrates when the air springs are connected to nodes directly and the weight of the vehicle is reduced the first and the last crossmembers, thus longitudinal beams are loaded with constant bending. To keep the lattice in equilibrium state there are two force systems. All the load vectors are $F$. This examination method was performed 6 and 7 crossmembers, but only 8 crossmembers lattice are shown on Fig. 12.

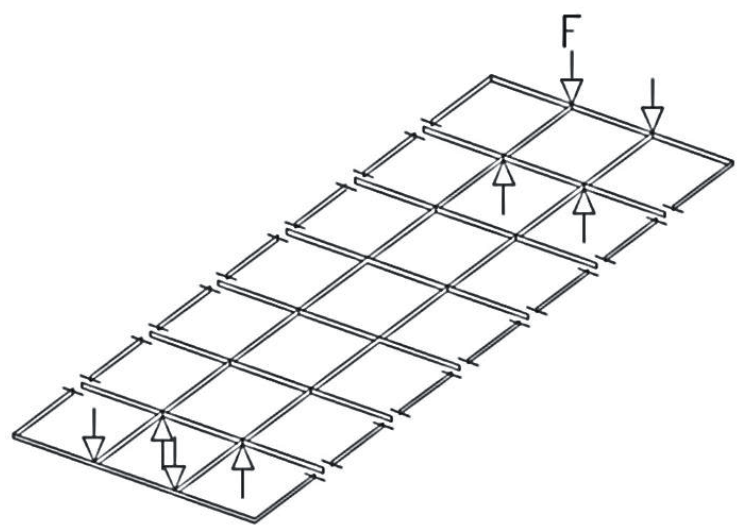

Fig. 12 Lattice structure with $\mathrm{S}_{1} \mathrm{~S}_{2}$ load and 8 crossmembers

The following coefficients are must be calculated to the compatibility equation (bending and shear).

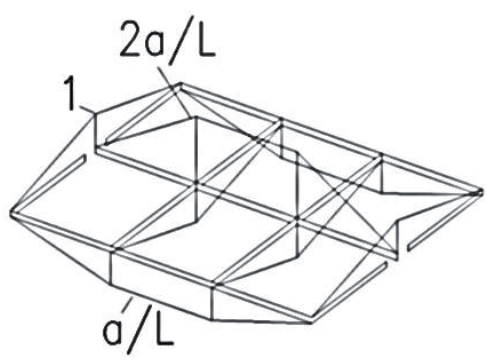

Fig. $13 \mathrm{~m}_{1}$ :Bending moment from $x 1$ unit load

$$
\begin{aligned}
& \delta_{11}^{B}=\frac{4 L}{3}\left(\frac{1}{I^{\prime}}+\frac{1}{I^{\prime \prime}}\right)+\frac{6 a^{2}}{3 I L^{2}}(2 a+3 b) \\
& \delta_{12}^{B}=\frac{L}{3}\left(\frac{1}{I^{\prime}}+\frac{1}{I^{\prime \prime}}\right)-\frac{4 a^{2}}{3 I L^{2}}(2 a+3 b)
\end{aligned}
$$




$$
\delta_{13}^{B}=\frac{a^{2}}{3 I L^{2}}(2 a+3 b)
$$

And the bending moment of basic system due to outer load:

$$
\begin{gathered}
\delta_{01}^{B}=-\frac{5}{3} \frac{F L^{2}}{I^{\prime \prime}} \\
\delta_{02}^{B}=\delta_{03}^{B}=-2 \frac{F L^{2}}{I^{\prime \prime}}
\end{gathered}
$$

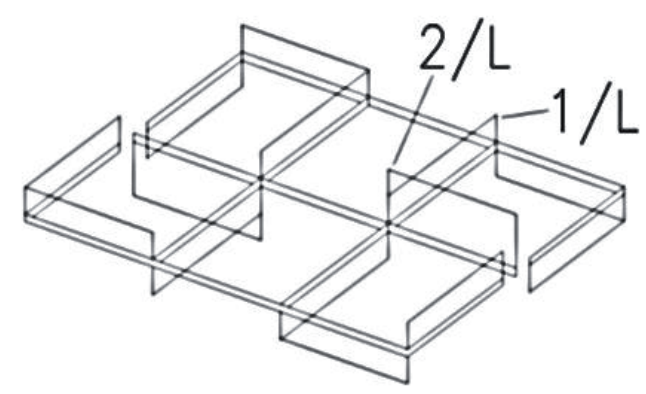

Fig. $14 \mathrm{q}_{1}$ : Shear from $x 1$ unit load

$$
\begin{gathered}
\delta_{11}^{S}=\frac{4}{L}\left(\frac{1}{A^{\prime}}+\frac{1}{A^{\prime \prime}}\right)+\frac{12 a}{L^{2} A} \\
\delta_{12}^{S}=-\frac{2}{L}\left(\frac{1}{A^{\prime}}+\frac{1}{A^{\prime \prime}}\right)-\frac{8 a}{L^{2} A} \\
\delta_{13}^{S}=\frac{2 a}{L^{2} A} \\
\delta_{01}^{S}=-\frac{2 F}{A^{\prime \prime}} \\
\delta_{02}^{S}=\delta_{03}^{S}=0
\end{gathered}
$$

The summarized coefficients of the compatibility equation are the following, considering the bending and shear:

$$
\begin{gathered}
\delta_{11}=\frac{4 L}{3}\left(\frac{1}{I^{\prime}}+\frac{1}{I^{\prime \prime}}\right)+\frac{6 a^{2}}{3 I L^{2}}(2 a+3 b) \\
+\frac{4}{L}\left(\frac{1}{A^{\prime}}+\frac{1}{A^{\prime \prime}}\right)+\frac{12 a}{L^{2} A} \\
\delta_{12}=\frac{L}{3}\left(\frac{1}{I^{\prime}}+\frac{1}{I^{\prime \prime}}\right)-\frac{4 a^{2}}{3 I L^{2}}(2 a+3 b)-\frac{2}{L}\left(\frac{1}{A^{\prime}}+\frac{1}{A^{\prime \prime}}\right)-\frac{8 a}{L^{2} A} \\
\delta_{13}=\frac{a^{2}}{3 I L^{2}}(2 a+3 b)+\frac{2 a}{L^{2} A} \\
\delta_{01}=-\frac{5}{3} \frac{F L^{2}}{I^{\prime \prime}}-\frac{2 F}{A^{\prime \prime}}
\end{gathered}
$$

$$
\delta_{02}=\delta_{03}=-2 \frac{F L^{2}}{I^{\prime \prime}}
$$

When $n=8$, the compatibility equation is written as:

$$
\left[\begin{array}{ccc}
\delta_{11} & \delta_{12} & \delta_{13} \\
\delta_{12} & \delta_{11} & \left(\delta_{12}+\delta_{13}\right) \\
\delta_{13} & \left(\delta_{12}+\delta_{13}\right) & \left(\delta_{11}+\delta_{12}\right)
\end{array}\right] *\left[\begin{array}{c}
x 1 \\
x 2 \\
x 3
\end{array}\right]+\left[\begin{array}{c}
\delta_{01} \\
\delta_{02} \\
\delta_{03}
\end{array}\right]=0
$$

If the structure has 6 crossmembers the compatibility matrix is created easily from (19) with first row and column removal. In case of $n$ is odd:

$$
\left[\begin{array}{ccc}
\delta_{11} & \delta_{12} & \delta_{13} \\
\delta_{12} & \left(\delta_{11}+\delta_{13}\right) & \delta_{12} \\
\delta_{13} & \delta_{12} & \frac{\delta_{11}}{2}
\end{array}\right] *\left[\begin{array}{c}
x 1 \\
x 2 \\
x 3
\end{array}\right]+\left[\begin{array}{c}
\delta_{01} \\
\delta_{02} \\
\frac{\delta_{03}}{2}
\end{array}\right]=0
$$

Here is opportunity to converse to $\gamma$ and $\gamma^{\prime}$ parameters.

$$
\left[\begin{array}{ccc}
\frac{\delta_{11}}{\delta_{13}} & \frac{\delta_{12}}{\delta_{13}} & 1 \\
\frac{\delta_{12}}{\delta_{13}} & \frac{\delta_{11}}{\delta_{13}} & \frac{\delta_{12}}{\delta_{13}}+1 \\
1 & \frac{\delta_{12}}{\delta_{13}}+1 & \frac{\delta_{11}+\delta_{12}}{\delta_{13}}
\end{array}\right] *\left[\begin{array}{l}
x 1 \\
x 2 \\
x 3
\end{array}\right]+\left[\begin{array}{c}
\frac{\delta_{01}}{\delta_{13}} \\
\frac{\delta_{02}}{\delta_{13}} \\
\frac{\delta_{03}}{\delta_{13}}
\end{array}\right]=0
$$

In other way:

$$
\begin{aligned}
& {\left[\begin{array}{ccc}
4\left(\frac{\gamma+C \gamma^{\prime}}{C+1}\right)+6 & \frac{\gamma-2 C \gamma^{\prime}}{C+1}-4 & 1 \\
\frac{\gamma-2 C \gamma^{\prime}}{C+1}-4 & 4\left(\frac{\gamma+C \gamma^{\prime}}{C+1}\right)+6 & \frac{\gamma-2 C \gamma^{\prime}}{C+1}-3 \\
1 & \frac{\gamma-2 C \gamma^{\prime}}{C+1}-3 & \frac{5 \gamma+2 C \gamma^{\prime}}{C+1}+2
\end{array}\right]} \\
& *\left[\begin{array}{c}
x 1 \\
x 2 \\
x 3
\end{array}\right]+\left[\begin{array}{l}
D_{1} \\
D_{2} \\
D_{2}
\end{array}\right]=0
\end{aligned}
$$

where the new parameters are:

$$
\begin{gathered}
\gamma=\frac{I L^{3}}{a^{2}(2 a+3 b)}\left(\frac{1}{I^{\prime}}+\frac{1}{I^{\prime \prime}}\right), \\
\gamma^{\prime}=\frac{L A}{2 a}\left(\frac{1}{A^{\prime}}+\frac{1}{A^{\prime \prime}}\right), \\
C=\frac{6 I}{a A(2 a+3 b)},
\end{gathered}
$$




$$
D_{1}=\frac{-5 F L^{4} I}{a^{2} I^{\prime \prime}(2 a+3 b)(C+1)}-\frac{2 F C L^{2} A}{2 a A^{\prime \prime}(C+1)} \text { and }
$$

$$
D_{2}=\frac{-6 F L^{4} I}{a^{2} I^{\prime \prime}(2 a+3 b)(C+1)}
$$

If all the former parameters set to value 1, distribution of the bending moment on side-wall beam and longitudinal beam can be seen (Fig. 15 and Fig. 16).

On figures the $x_{i} / F L$ ratios can be seen in function of the $j$ th crossmember.

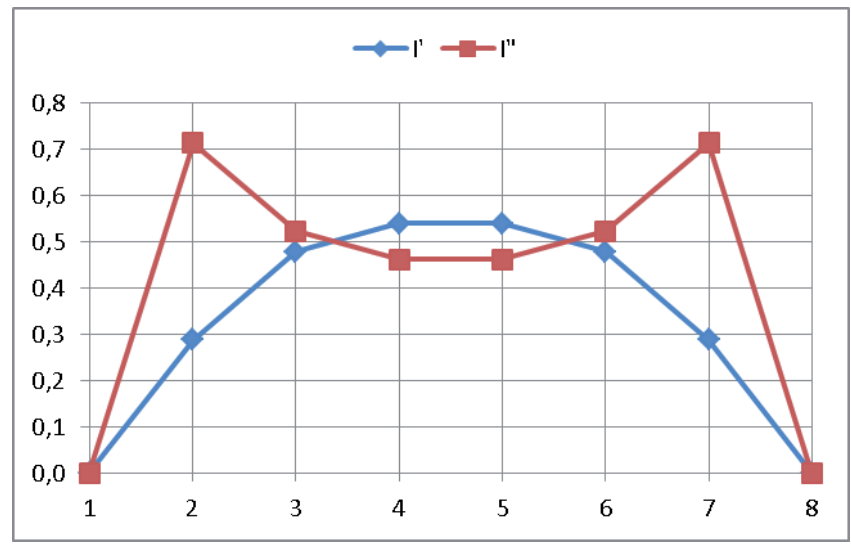

Fig. 15 Bending moment distribution on the side-wall beam ( $\left.I^{\prime}\right)$ and longitudinal beam (I’) (without shear)

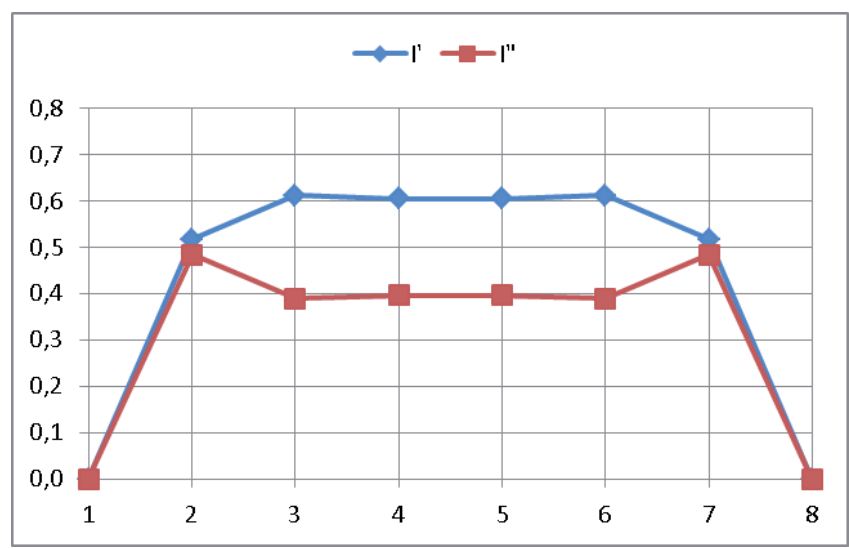

Fig. 16 Bending moment with distribution on the side-wall beam $\left(I^{\prime}\right)$ and longitudinal beam (I") (with shear)

If $a, b$ and $L$ parameters are set to general value

( $a=0,7 \mathbf{m} b=1,5 a$ and $L=1,25 \mathrm{~m}$ ), the digraph are modified (Fig. 17 and Fig. 18).

In the figures (Fig. 17 and Fig. 18) can be seen that $50 \%$ of the outer load goes to the side-wall beam and the rest $\sim 50 \%$ stays on the longitudinal beam. According to the original assumption $(I \rightarrow \infty)$ the model is acceptable, but the reduced calculation has got inaccuracy. The difference between calculated value and mean can be seen in Table 1-2.

In the following load cases the shear is neglected, thus to make the calculation easier.

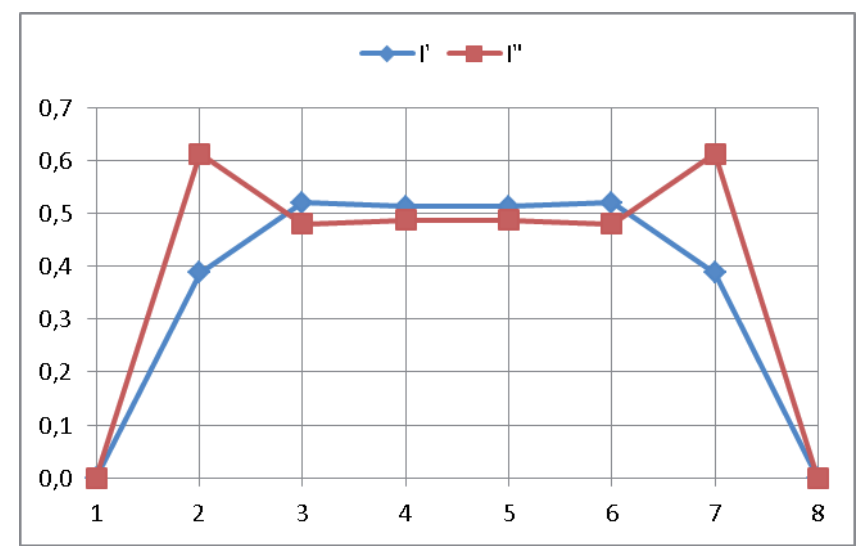

Fig. 17 Bending moment distribution on the side-wall beam $\left(I^{\prime}\right)$ and longitudinal beam (I") (without shear)

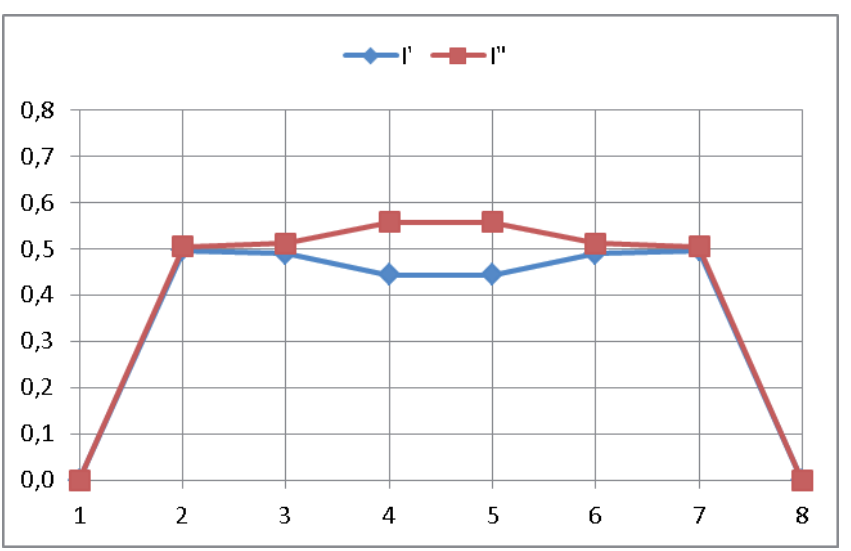

Fig. 18 Bending moment with distribution on the side-wall beam ( $\left.I^{\prime}\right)$ and longitudinal beam (I’) (with shear)

Table 1 Inaccuracy from the mean value (50\%), without shear

\begin{tabular}{ccccccc}
\hline Crossmember & 2 & 3 & 4 & 5 & 6 & 7 \\
\hline $\begin{array}{c}\text { Side-wall beam } \\
\text { (without shear) }\end{array}$ & $-11 \%$ & $+2 \%$ & $+1 \%$ & $+1 \%$ & $+2 \%$ & $-11 \%$ \\
\hline $\begin{array}{c}\text { Long. beam } \\
\text { (without shear) }\end{array}$ & $+11 \%$ & $-2 \%$ & $-1 \%$ & $-1 \%$ & $-2 \%$ & $+11 \%$ \\
\hline
\end{tabular}

Table 2 Inaccuracy from the mean value (50\%), with shear

\begin{tabular}{ccccccc}
\hline Crossmember & 2 & 3 & 4 & 5 & 6 & 7 \\
\hline $\begin{array}{c}\text { Side-wall beam } \\
\text { (with shear) }\end{array}$ & 0 & $-1 \%$ & $-6 \%$ & $-6 \%$ & $-1 \%$ & 0 \\
\hline $\begin{array}{c}\text { Long. beam (with } \\
\text { shear) }\end{array}$ & 0 & $+1 \%$ & $+6 \%$ & $+6 \%$ & $+1 \%$ & 0 \\
\hline
\end{tabular}

\section{Semi symmetric loads $\left(S_{1} A_{2}\right)$}

The outer load is modified, antimetric for the lateral symmetry plane. This load case illustrates when the vehicle accelerates or decelerates. In the case two different force systems is applied. The first system is $F_{A}$, the second is $F_{B}$. The relation between the two systems is:

$$
F_{A}=\left(\frac{n-3}{n-1}\right) F_{B}
$$




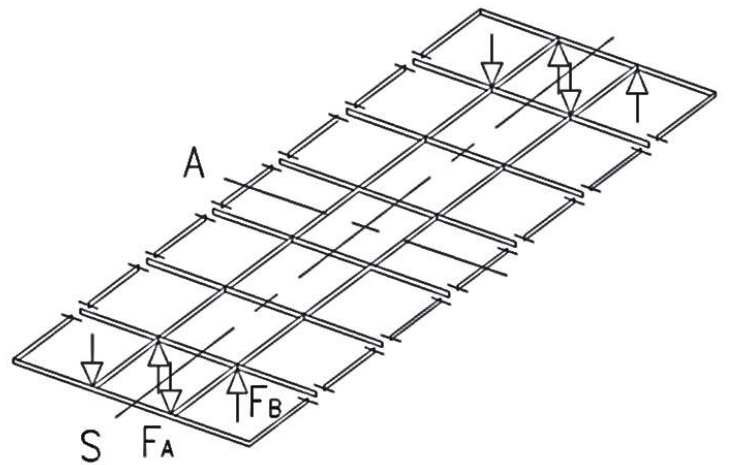

Fig. 19 Lattice structure with $S_{1} A_{2}$ load and 8 crossmembers

The coefficients for the compatibility equation are:

$$
\begin{gathered}
\delta_{11}=\frac{4 L}{3}\left(\frac{1}{I^{\prime}}+\frac{1}{I^{\prime \prime}}\right)+\frac{6 a^{2}}{3 I L^{2}}(2 a+3 b) \\
\delta_{12}=\frac{L}{3}\left(\frac{1}{I^{\prime}}+\frac{1}{I^{\prime \prime}}\right)-\frac{4 a^{2}}{3 I L^{2}}(2 a+3 b) \\
\delta_{13}=\frac{a^{2}}{3 I L^{2}}(2 a+3 b) \\
\delta_{02}=-\frac{18}{21} \frac{F_{B} L^{2}}{I^{\prime \prime}} \\
\delta_{03}=-\frac{6}{21} \frac{F_{B} L^{2}}{I^{\prime \prime}}
\end{gathered}
$$

The compatibility equation:

$$
\left[\begin{array}{ccc}
\frac{\delta_{11}}{\delta_{13}} & \frac{\delta_{12}}{\delta_{13}} & 1 \\
\frac{\delta_{12}}{\delta_{13}} & \frac{\delta_{11}}{\delta_{13}} & \frac{\delta_{12}}{\delta_{13}}+1 \\
1 & \frac{\delta_{12}}{\delta_{13}}+1 & \frac{\delta_{11}+\delta_{12}}{\delta_{13}}
\end{array}\right] *\left[\begin{array}{c}
x 1 \\
x 2 \\
x 3
\end{array}\right]+\left[\begin{array}{l}
\frac{\delta_{01}}{\delta_{13}} \\
\frac{\delta_{02}}{\delta_{13}} \\
\frac{\delta_{03}}{\delta_{13}}
\end{array}\right]=0
$$

In other way:

$$
\left[\begin{array}{ccc}
4 \gamma+6 & \gamma-4 & 1 \\
\gamma-4 & 4 \gamma+6 & \gamma-3 \\
1 & \gamma-3 & 5 \gamma+2
\end{array}\right] *\left[\begin{array}{c}
x 1 \\
x 2 \\
x 3
\end{array}\right]+\left[\begin{array}{c}
D_{1} \\
D_{2} \\
D_{3}
\end{array}\right]=0
$$

here

$$
\gamma=\frac{I L^{3}}{a^{2}(2 a+3 b)}\left(\frac{1}{I^{\prime}}+\frac{1}{I^{\prime \prime}}\right),
$$

and

$$
D_{1}=-\frac{23}{7} \frac{F_{B} L^{4} I}{a^{2} I^{\prime \prime}(2 a+3 b)}
$$

$$
\begin{aligned}
& D_{2}=-\frac{18}{7} \frac{F_{B} L^{4} I}{a^{2} I^{\prime \prime}(2 a+3 b)} \\
& D_{3}=-\frac{6}{7} \frac{F_{B} L^{4} I}{a^{2} I^{\prime \prime}(2 a+3 b)}
\end{aligned}
$$

If all the parameters set to value 1 , distribution of the bending moment on side-wall beam and longitudinal beam is the following (Fig. 20).

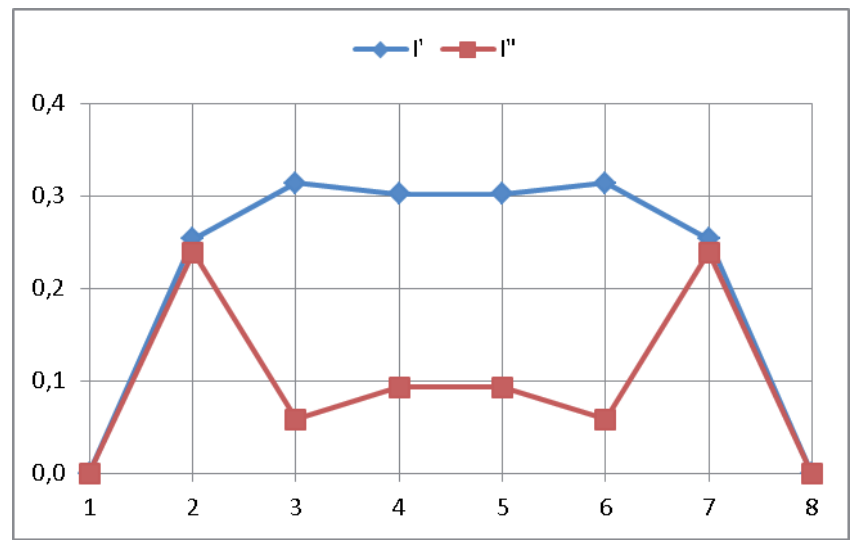

Fig. 20 Bending moment distribution on the side-wall beam ( $\left.I^{\prime}\right)$ and longitudinal beam ( $\left.I^{\prime \prime}\right)$ (without shear)

If $a, b$ and $L$ parameters are set to general value ( $a=0,7 \mathrm{~m} \quad b=1,5 a$ and $L=1,25 \mathrm{~m}$ ), the digraph is modified (Fig. 21).

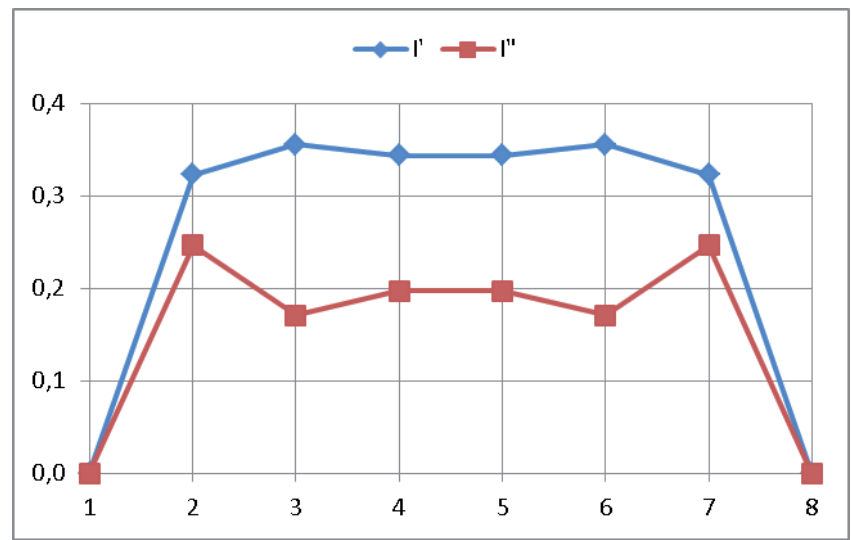

Fig. 21 Bending moment distribution on the side-wall beam $\left(I^{\prime}\right)$ and longitudinal beam (I’) (without shear)

\section{Semi symmetric loads $\left(A_{1} S_{2}\right)$}

The examination method is similar to the previous case, but the bending moment not only depend on bending inertias, but geometric parameters ( $a$ and $b$ ) also. 


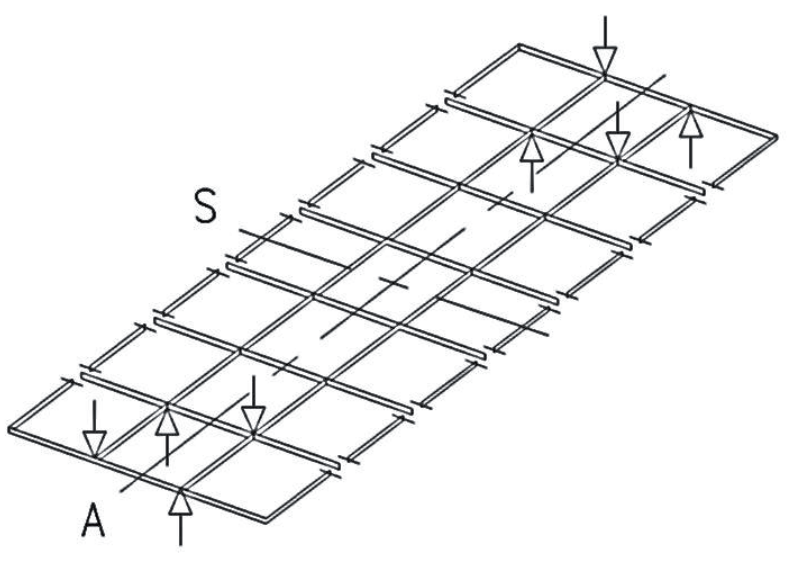

Fig. 22 Lattice structure with $\mathrm{A}_{1} \mathrm{~S}_{2}$ load and 8 crossmembers

Similarly to the outer load, the unit load is modified as well. where

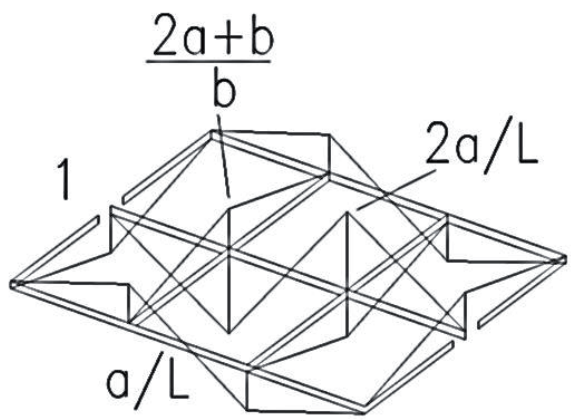

Fig. 23 Bending moment from $x 1$ unit load

The following coefficients are must be calculated to the compatibility equation (only bending).

$$
\begin{gathered}
\delta_{11}=\frac{4 L}{3}\left(\frac{1}{I^{\prime}}+\frac{1}{I^{\prime \prime}}\left(\frac{2 a+b}{b}\right)^{2}\right)+\frac{2 a^{2}}{I L^{2}}(2 a+b) \\
\delta_{12}=\frac{L}{3}\left(\frac{1}{I^{\prime}}+\frac{1}{I^{\prime \prime}}\left(\frac{2 a+b}{b}\right)^{2}\right)-\frac{4 a^{2}}{3 I L^{2}}(2 a+b) \\
\delta_{13}=\frac{a^{2}}{3 I L^{2}}(2 a+b)
\end{gathered}
$$

And the bending moment of basic system due to outer load:

$$
\begin{gathered}
\delta_{01}=\frac{5}{3} \frac{F L^{2}}{I^{\prime \prime}}\left(\frac{2 a+b}{b}\right) \\
\delta_{02}=\delta_{03}^{B}=2 \frac{F L^{2}}{I^{\prime \prime}}\left(\frac{2 a+b}{b}\right)
\end{gathered}
$$

Finally, compatibility equation is written as:

$$
\left[\begin{array}{ccc}
\delta_{11} & \delta_{12} & \delta_{13} \\
\delta_{12} & \delta_{11} & \delta_{12}+\delta_{13} \\
\delta_{13} & \delta_{12}+\delta_{13} & \delta_{11}+\delta_{12}
\end{array}\right] *\left[\begin{array}{l}
x 1 \\
x 2 \\
x 3
\end{array}\right]+\left[\begin{array}{l}
\delta_{01} \\
\delta_{02} \\
\delta_{03}
\end{array}\right]=0
$$

The equation system with the new parameter:

$$
\begin{aligned}
& {\left[\begin{array}{ccc}
\frac{\delta_{11}}{\delta_{13}} & \frac{\delta_{12}}{\delta_{13}} & 1 \\
\frac{\delta_{12}}{\delta_{13}} & \frac{\delta_{11}}{\delta_{13}} & \frac{\delta_{12}}{\delta_{13}}+1 \\
1 & \frac{\delta_{12}}{\delta_{13}}+1 & \frac{\delta_{11}+\delta_{12}}{\delta_{13}}
\end{array}\right] *\left[\begin{array}{l}
x 1 \\
x 2 \\
x 3
\end{array}\right]+\left[\begin{array}{l}
\frac{\delta_{01}}{\delta_{13}} \\
\frac{\delta_{02}}{\delta_{13}} \\
\frac{\delta_{03}}{\delta_{13}}
\end{array}\right]=0} \\
& {\left[\begin{array}{ccc}
4 \gamma+6 & \gamma-4 & 1 \\
\gamma-4 & 4 \gamma+6 & \gamma-3 \\
1 & \gamma-3 & 5 \gamma+2
\end{array}\right] *\left[\begin{array}{l}
x 1 \\
x 2 \\
x 3
\end{array}\right]+\left[\begin{array}{c}
D_{1} \\
D_{2} \\
D_{2}
\end{array}\right]=0}
\end{aligned}
$$

$$
\begin{aligned}
& D_{1}=\frac{5 F L^{4} I}{a^{2} I^{\prime \prime}\left(\frac{(2 a+b)^{2}}{b}\right)} \\
& D_{2}=\frac{6 F L^{4} I}{a^{2} I^{\prime \prime}\left(\frac{(2 a+b)^{2}}{b}\right)}
\end{aligned}
$$

If all the parameters set to value 1, distribution of the bending moment on side-wall beam and longitudinal beam are the following (Fig. 24).

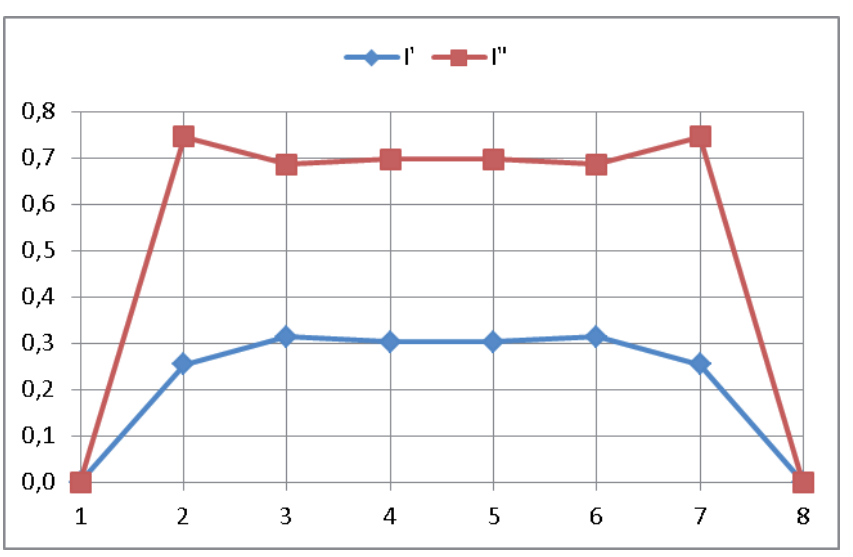

Fig. 24 Bending moment distribution on the side-wall beam (I') and longitudinal beam (I") (without shear)

If the $a, b$ and $L$ parameters are set to general value ( $a=$ $0,7 \mathrm{~m} \quad b=1,5 a$ and $L=1,25 \mathrm{~m}$ ), the digraph is modified a bit (Fig. 25). 


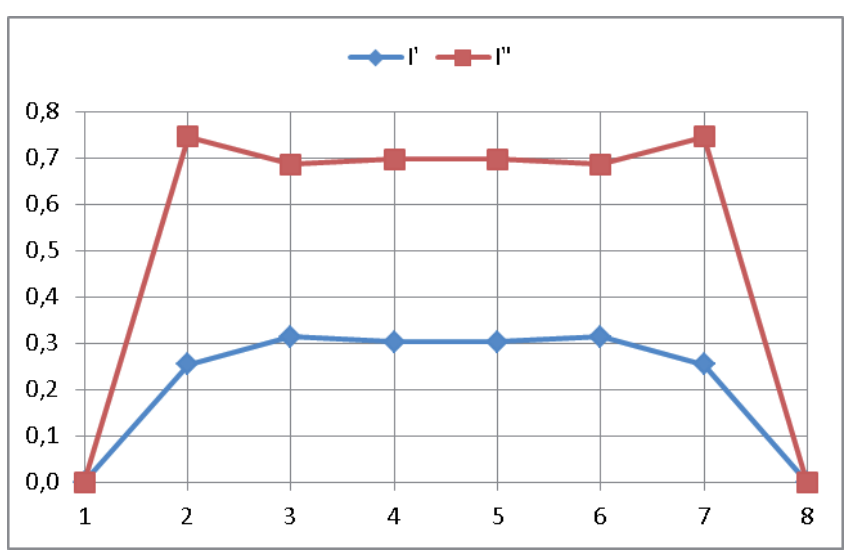

Fig. 25 Bending moment distribution on the side-wall beam (I') and longitudinal beam (I") (without shear)

\section{Conclusion}

In this paper three load cases are introduced $\left(\mathrm{S}_{1} \mathrm{~S}_{2}, \mathrm{~S}_{1} \mathrm{~A}_{2}\right.$ and $\mathrm{A}_{1} \mathrm{~S}_{2}$ ) of four. The mentioned structure can be described with $\delta$ coefficient or $\gamma$ parameters as well. Latter are applicable in reduced form for further investigations. The first case is when the load is symmetric both the longitudinal and lateral symmetry planes called $\mathrm{S}_{1} \mathrm{~S}_{2}$. The original assumption was: the bending moment from the outer load can be divided in ratio of the longitudinal and side-wall beams if the outer load is $\mathrm{S}_{1}$ (only long. beams are loaded). If the outer load is antimetric then can be divided in ratio of the beam inertias and $a$ and $b$ dimension. In all cases $I \rightarrow \infty$ is assumed. This paper examines different load (act only on long. beams) cases when $I$ is sufficient large.

On all diagrams calculated and estimated $I \rightarrow \infty$ bending moment distribution can be seen with black and green curves.

If the bending inertia of the side-wall and longitudinal beams approximately equally magnitude, the $50 \%$ of bending moment from the outer load acts on longitudinal beam, and $50 \%$ of the bending moment goes to side-wall beam (Fig 26, 27 and 28).

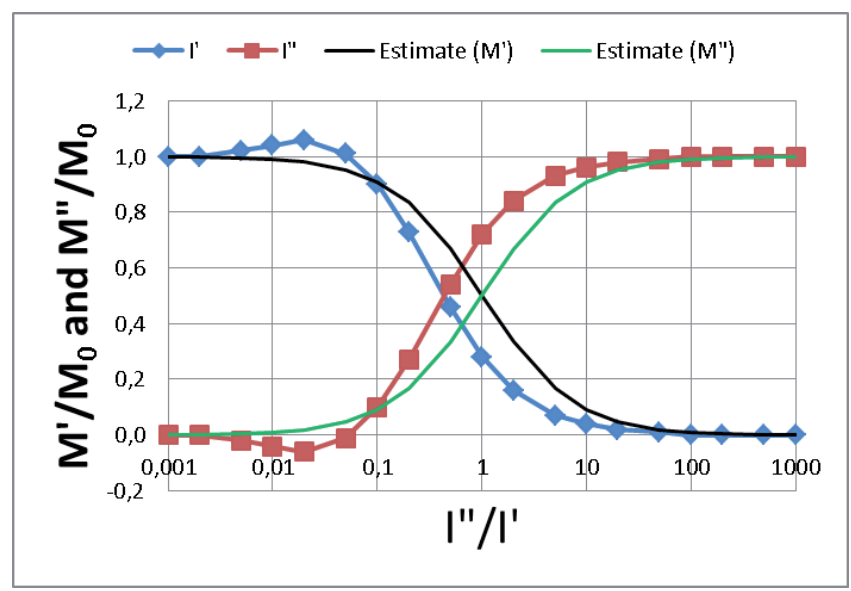

Fig. 26 Bending moment distribution on the side-wall beam $\left(I^{\prime}\right)$ and longitudinal beam ( $I^{\prime}$ ) (without shear) $I=0,01$

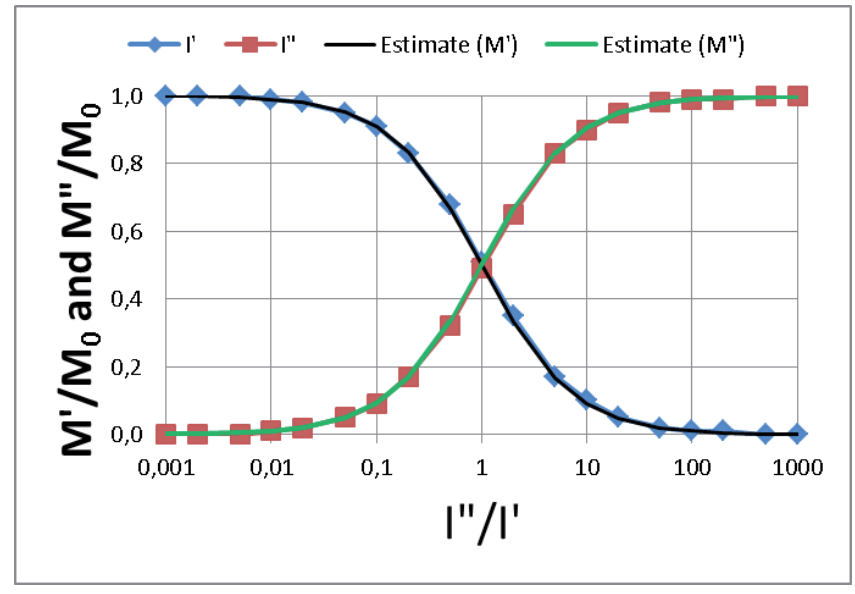

Fig. 27 Bending moment distribution on the side-wall beam ( $\left.I^{\prime}\right)$ and longitudinal beam ( $\left.I^{\prime}\right)$ (without shear) $I=1$

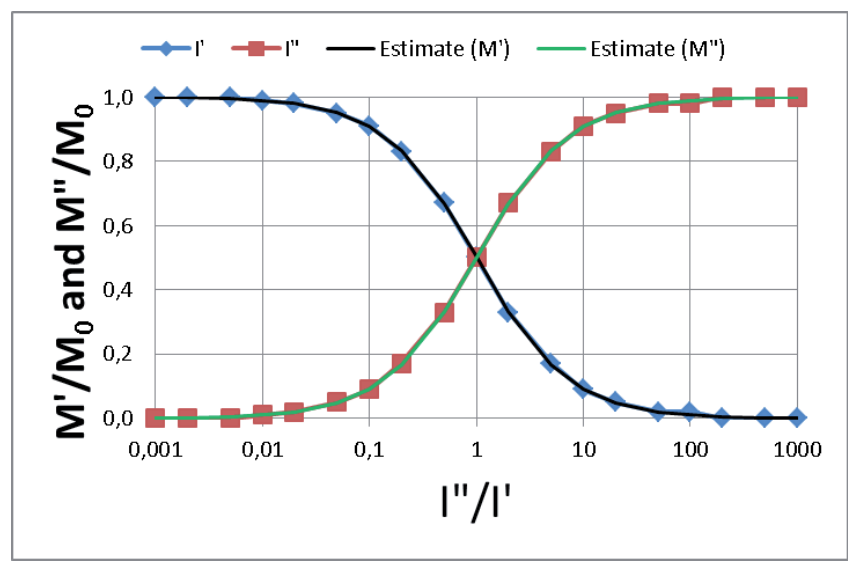

Fig. 28 Bending moment distribution on the side-wall beam ( $\left.I^{\prime}\right)$ and longitudinal beam ( ${ }^{\prime}$ ') (without shear) $I=100$

In the second case when the load is $\mathrm{S}_{1} \mathrm{~A}_{2}$, near the similar result is giving similar to $S_{1} S_{2}$, because the outer load is symmetric for the longitudinal plane (Fig 29, 30 and 31). Bending moment distribution is symmetric.

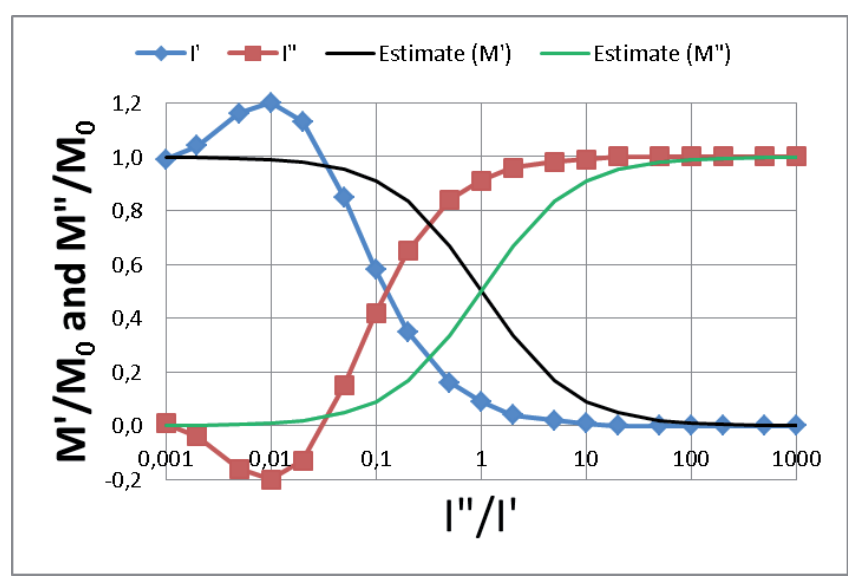

Fig. 29 Bending moment distribution on the side-wall beam ( $\left.I^{\prime}\right)$ and longitudinal beam ( $\left.I^{\prime}\right)$ (without shear) $I=0,01$ 


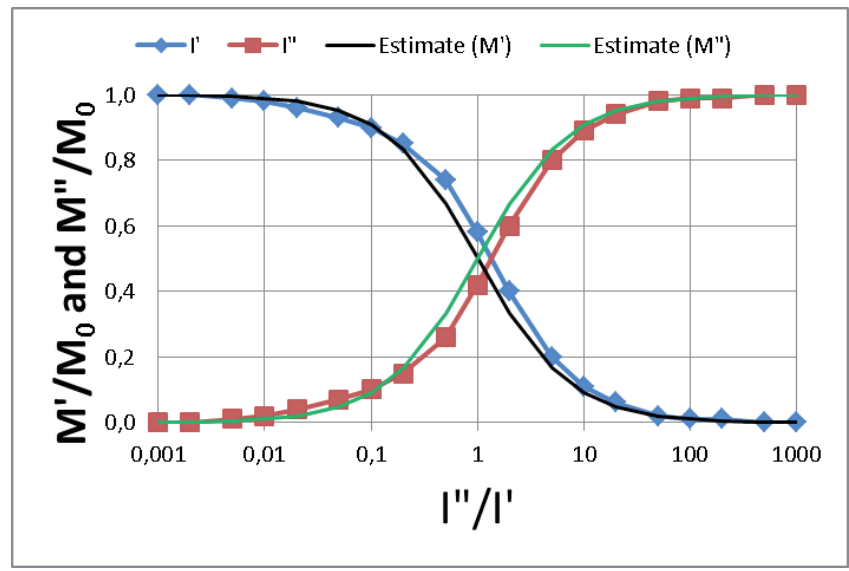

Fig. 30 Bending moment distribution on the side-wall beam $\left(I^{\prime}\right)$ and longitudinal beam ( $\left.I^{\prime}\right)$ (without shear) $I=1$

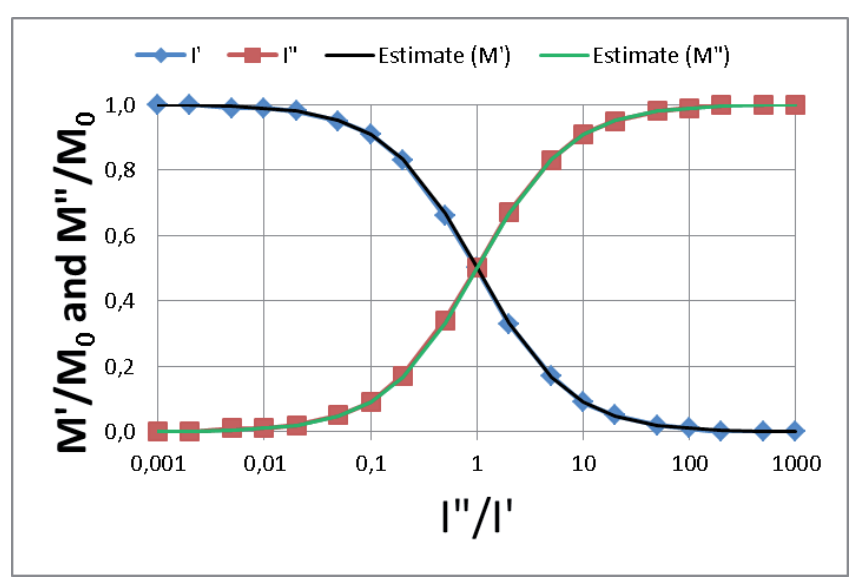

Fig. 31 Bending moment distribution on the side-wall beam $\left(I^{\prime}\right)$ and longitudinal beam ( $\left.I^{\prime}\right)$ (without shear) $I=100$

In the third case $\left(\mathrm{A}_{1} \mathrm{~S}_{2}\right)$, near the inertias ratio appears the effect of $a$ and $b$ in bending moment distribution. If $a$ and $b$ are set to practice value ( $a=0,7 \mathrm{~m}, b=1,05 \mathrm{~m})$, the bending moment distribution can be seen on Fig. 32-34 in function of the sidewall and longitudinal beam inertias ratio.

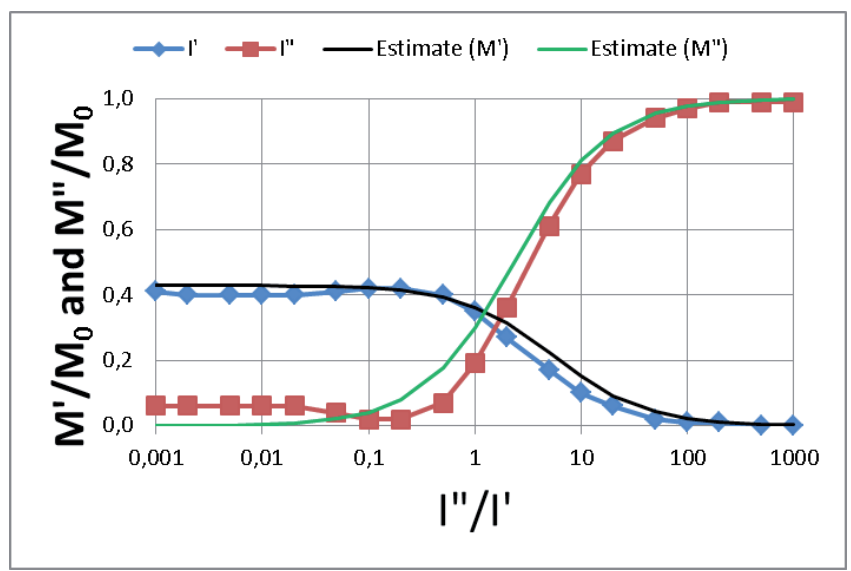

Fig. 32 Bending moment distribution on the side-wall beam $\left(I^{\prime}\right)$ and longitudinal beam ( $I^{\prime \prime}$ ) (without shear) $I=0,01$

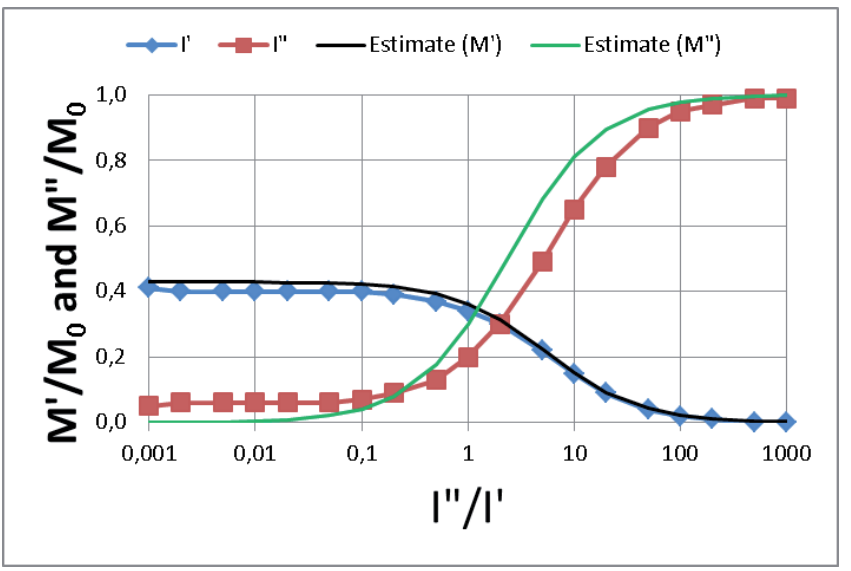

Fig. 33 Bending moment distribution on the side-wall beam ( $\left.I^{\prime}\right)$ and longitudinal beam ( $\left.I^{\prime}\right)$ (without shear) $I=1$

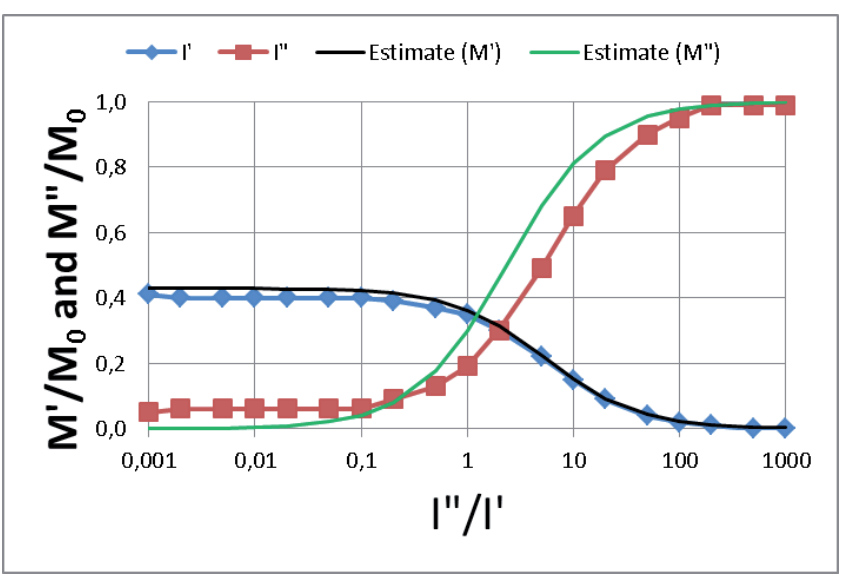

Fig. 34 Bending moment distribution on the side-wall beam $\left(I^{\prime}\right)$ and longitudinal beam ( $\left.I^{\prime \prime}\right)$ (without shear) $I=100$

If the bending inertia of the side-wall and longitudinal beams approximately equally magnitude, the $\sim 20 \%$ of bending moment from the outer load acts on longitudinal beam, and $\sim 35 \%$ goes to side-wall beam. If the bending inertia value of the crossmember at least equal with the other beams inertia, the distribution of the longitudinal beam bending moment estimate is acceptable for practical use, when:

$$
I^{\prime} \approx I^{\prime \prime} \leq I
$$

\section{References}

Erz, K. (1957) Über die durch Unebenheiten der Fahrbahn hervorgerufene Verdrehung von Strassenfahrzeugen. (Torsion of the road vehicles caused by bumpy road.) ATZ. 59. pp. 89-96, 163-170, 345-347, 371-375 (in German) Galambosi, F., Michelberger, P., Rózsa, P. (1982) Preliminary Approximate Analysis of Bending Stresses in Lattice-like Vehicle Structure. Periodica Polytechnica Transportation Engineering. 10 (2). pp. 67-82.

Harth, P., Michelberger, P. (2014) Development of a new method planar-frame structure examination in commercial vehicle design. Periodica Polytechnica Transportation Engineering. 42 (1). pp. 19-25. DOI: 10.3311/PPtr.7260 
Michelberger, P. (1968) Válogatott fejezetek a könnyüszerkezetek szilárdságtanából I. (Selected chapters from mechanics of lightweight structures I.) Budapest: Tankönyvkiadó. (in Hungarian)

Palotás, L. (1953) Tartórácsok számitása. (Calculation of racks.) Budapest: Közlekedési Kiadó. (in Hungarian)

Pristyák, A. (1997) Analysis of dinamics loads of the lattice type mast structure of a tower crane using simulation method. Periodica Polytechnica Transportation Engineering. 25 (1-2). pp. 103-111.

Schiling, W. (1925) Statik der Bodenkonstruktion der Schiffe. (Static of the floor structure of ship.) Berlin: Springer Verlag. (in German) 